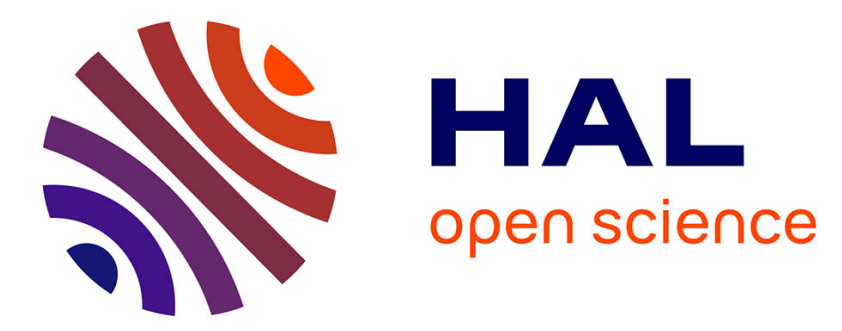

\title{
Efficient versatile-repetition-rate picosecond source for material processing applications
}

Christoph Gerhard, Frédéric Druon, Pierre Blandin, Marc Hanna, François

Balembois, Patrick Georges, Franck Falcoz

\section{- To cite this version:}

Christoph Gerhard, Frédéric Druon, Pierre Blandin, Marc Hanna, François Balembois, et al.. Efficient versatile-repetition-rate picosecond source for material processing applications. Applied optics, 2008, 47 (7), pp 967-974. hal-00531818

\section{HAL Id: hal-00531818 \\ https://hal.science/hal-00531818}

Submitted on 30 Mar 2012

HAL is a multi-disciplinary open access archive for the deposit and dissemination of scientific research documents, whether they are published or not. The documents may come from teaching and research institutions in France or abroad, or from public or private research centers.
L'archive ouverte pluridisciplinaire HAL, est destinée au dépôt et à la diffusion de documents scientifiques de niveau recherche, publiés ou non, émanant des établissements d'enseignement et de recherche français ou étrangers, des laboratoires publics ou privés. 


\title{
Efficient versatile-repetition-rate picosecond source for material processing applications
}

\author{
Christoph Gerhard, ${ }^{1}$ Frédéric Druon, ${ }^{1, *}$ Pierre Blandin, ${ }^{1}$ Marc Hanna, ${ }^{1}$ \\ François Balembois, ${ }^{1}$ Patrick Georges, ${ }^{1}$ and F. Falcoz ${ }^{2}$ \\ ${ }^{1}$ Laboratoire Charles Fabry del'Institut d'Optique, CNRS, Université Paris-Sud, RD 128, 91127 Palaiseau, France \\ ${ }^{2}$ Thales Laser, Domaine de Corbeville, 91400 Orsay, France \\ ${ }^{\star}$ Corresponding author: frederic.druon@institutoptique.fr
}

Received 27 August 2007; revised 5 December 2007; accepted 20 December 2007; posted 7 January 2008 (Doc. ID 86925); published 28 February 2008

\begin{abstract}
We report on the development of an efficient and simple picosecond diode-pumped solid-state laser source with a versatile repetition rate (typically $1 \mathrm{~Hz}-1 \mathrm{MHz}$ ) for material processing applications. The laser source is based on a $4 \mathrm{MHz}$ repetiton rate mode-locked oscillator and a passive 3D multipass amplifier both based on Nd:YVO ${ }_{4}$ crystals. Micromachining experiments were performed to study the influence of pulse energy on the machining quality for $\mathrm{Al}, \mathrm{Cu}$, paper, and glass. @ 2008 Optical Society of America OCIS codes: $140.3390,140.4050$.
\end{abstract}

\section{Introduction}

Athermal micromachining is now admitted to be a very interesting alternative to obtain nice and precise material cutting and drilling without collateral damage. In fact, long pulse (nanosecond) processing shows limitations due to a heating-based ablation process. This process induces microcracking and debris redeposition of the droplets created during the operation. These effects are very deleterious for precise micromachining. Nevertheless, the nanosecond lasers are relatively low cost and appropriate for many applications. High precision processing can be obtained using an excimer UV laser, which process is not based on heat but on chemical-bond breaking. The alternative way is to use ultrashort pulsed sources with high peak power which involve ablation by plasma [1-4]. This Coulomb explosion is a nonthermal ablation mechanism [5-7]. Both picosecond and femtosecond pulses have been demonstrated to be very efficient for high-precision material processing with sharp edges and the absence of material dropping on the vicinity surface.

0003-6935/08/070967-08\$15.00/0

(C) 2008 Optical Society of America
The most established systems using this ablation technique are incontestably the femtosecond systems based on Ti:sapphire crystals and more recently on Yb-doped materials [8-12]. Using these femtosecond lasers, many works have been performed showing advantages in terms of micromachining efficiency and quality. However, these lasers reveal a relatively complex architecture including an oscillator, a chirped pulse amplification (CPA) scheme with stretcher and compressor and regenerative amplifier. To reduce the cost of the overall system and to gain in simplicity and reliability, it is thus interesting to develop picosecond sources for micromachining [13]. Considering the optimal pulse duration, different research papers have shown a strong dependency on the type of material or the technique used during the process (single pulse, percussion, trepanning helical drilling, polarization, etc.) [2,3,14-18]. The conclusion indicated that the optimal for picosecond regime is around $10 \mathrm{ps}$ to reduce thermal effects and increase precision [3]. The picosecond systems have the advantage of using Nd-doped-based technology, which is diode pumped and very efficient. These laser chains do not require CPA configuration, which leads not only to simpler systems but also to important cost reduction. Some alternative commercial products are 
based on this technology. The weakest link of these standard products remains the expensive high repetition rate Pockels cell in a regenerative amplifier, which allows repetition rates up to $100 \mathrm{kHz}$. The absence of repetition rate limitation may also be very convenient for some applications [19]. More versatility in the repetition rate could be achieved with cost reduction if the regenerative amplifier could be removed. One way to do this is to take advantage of the very high gain of the $\mathrm{Nd}$-doped material, in particular the one of $\mathrm{Nd}: \mathrm{YVO}_{4}$, to replace the regenerative amplifier by a simple passive geometricmultipass amplifier. In this paper, we report on the development of an efficient and simple picosecond diode-pumped solid-state laser source with versatile repetition rate (typically $1 \mathrm{~Hz}-1 \mathrm{MHz}$ ) for material processing applications.

The laser source consists of an ultrastable $4 \mathrm{MHz}$ rate diode-pumped $\mathrm{Nd}: \mathrm{YVO}_{4}$ laser and a passive $3 \mathrm{D}$ multipass amplifier based on $\mathrm{Nd}: \mathrm{YVO}_{4}$ crystals (Fig. 1). Both oscillator and amplifier are pumped with $30 \mathrm{~W} 400 \mu \mathrm{m}$ fiber-coupled laser diodes. A standard low cost acousto-optic modulator (AOM) is used to control the repetition rate. The ultralow repetition rate oscillator uses a stable dual mode-locking (ML) technique. This low repetition rate oscillator has the advantages of, first, reducing the constraint on the performance of the modulator and, second, producing energetic pulses $(\sim 0.3 \mu \mathrm{J})$ allowing the use of a passive and simple 3D multipass amplifier. After the amplifier, material processing experiments have been performed on different materials such as metals, paper, or glass.

\section{Low Repetition Rate Mode-Locked Oscillator}

The oscillator is an ultrastable mode-locked $\mathrm{Nd}: \mathrm{YVO}_{4}$ laser operating at a repetition rate of $3.95 \mathrm{MHz}$ (corresponding to a cavity length of $38 \mathrm{~m}$ ). Due to potential applications of this source for industrial processing, care was taken to ensure the longterm reliability of the system [20]. The ultrastable regime is obtained combining two different techniques of ML: a semiconductor saturable absorber mirror (SESAM) [21] and, on the other hand, the quadratic polarization switching (QPS) using a nonlinear crystal [22-24]. In fact, to obtain the effect of passive ML, i.e., picosend pulse generation, the SESAM can be used in a wide range of laser cavities. However, SESAMs are extremely sensitive to burning damage when operating out of the optimized intracavity laser fluence [25], especially in the case of very low repetition rate $\overline{\mathrm{ML}}$ lasers. We experimentally observed that for very long cavities, parameters such as the focusing spot diameter on the SESAM or the intracavity power are very critical, and damage problems can be observed when these parameters are not correctly adjusted or when perturbations occur. On the other hand, the QPS is a ML technique based on the nonlinear polarization rotation in a type II nonlinear crystal (NLC). By introducing a polarizer between the amplifying medium and the NLC, a device with an intensity dependent transmission can be realized as explored by Couderc et al. [22-24]. Just by changing the orientation of the NLC versus the intracavity polarization, this technique is adjustable for any range of output power. Thus we demonstrated a stable ML Nd: $\mathrm{YVO}_{4}$ laser with an output power in the watt range at $3.65 \mathrm{MHz}$ repetition rate [20].

The oscillator (Fig. 1) was built around a $10 \mathrm{~mm}$ long, $0.1 \%$-doped $\mathrm{Nd}: \overline{\mathrm{Y}} \mathrm{VO}_{4}$ crystal pumped by a $400 \mu \mathrm{m}$ diameter fiber-coupled diode delivering up to $30 \mathrm{~W}$ at $808 \mathrm{~nm}$ (Lissotschenko Mikrooptik $\mathrm{GmbH}$, Dortmund, Germany). The laser waist in the crystal was evaluated using an $A B C D$ simulation to be $200 \mu \mathrm{m}$. In standard operating mode, the fluence on the laser crystal is $1 \mathrm{~mJ} / \mathrm{cm}^{2}$ and no damage was observed. The maximum incident power on the crystal was $27 \mathrm{~W}$. The saturable absorber semiconductor was a SESAM (BATOP GmbH, Jena, Germany) centered at $\lambda=1064 \mathrm{~nm}$ and with a saturable absorption of $1.8 \%$ and a saturation fluence of $70 \mu \mathrm{J} / \mathrm{cm}^{2}$. Thanks to the dual-ML technique, the

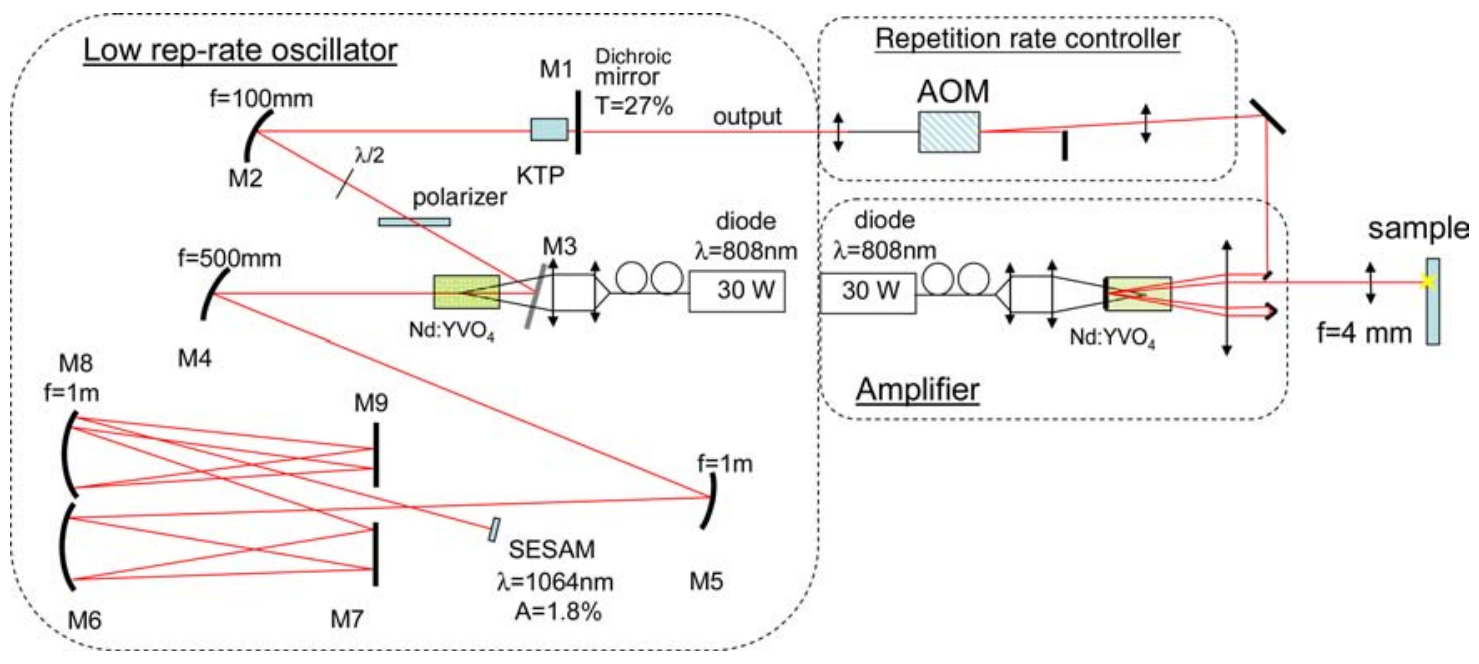

Fig. 1. (Color online) Experimental setup of the whole system. 
focus spot was not so critical and no concave mirror was used to focus the laser on the SESAM. The focus spot on the SESAM had a waist of $0.7 \mathrm{~mm}$ according to the $A B C D$-matrix simulation. At the other end of the cavity we used an output coupler mirror $(T=27 \%$ at $1064 \mathrm{~nm})$ combined with a type II $8 \mathrm{~mm}$ long KTP crystal to perform QPS. The QPS was optimized for the half-wave-plate angle of $5^{\circ} \mathrm{com}$ pared to one of the neutral axis of the nonlinear crystal (corresponding to an angle of $10^{\circ}$ for the incident laser polarization). To guarantee the stability of the ML laser, we operated it in the middle of the stable ML, i.e., with $24 \mathrm{~W}$ of incident pump power. The laser delivered an average power of $1.5 \mathrm{~W}$ at $4 \mathrm{MHz}$ with $15 \mathrm{ps} 0.38 \mu \mathrm{J}$ pulses. The autocorrelation trace and the spectrum of these pulses are represented in Fig. 2.

The advantages of operating the oscillator at a very low repetition rate are the following. First, the low repetition rate allows to reduce drastically the constraint on the pulse picker. In our case we could use a standard AOM with a very slightly focused beam, allowing a diffraction efficiency of $70 \%$. We also obtained a very easily tunable repetition rate from $1 \mathrm{MHz}$ down to $1 \mathrm{~Hz}$ with the advantage of decoupling the repetition rate and the saturation of the amplifier, in contrast with the case of a regenerative amplifier for which the pulse-topulse energy stability is an issue. Second, reducing the repetition rate allows having enough energy to consider a simple few-pass amplifier.

\section{3D Multipass Amplifier}

The amplifier consists in a two- or four-pass 3D amplifier [26] using a $10 \mathrm{~mm}$ long, 0.1\%-doped Nd:YVO crystal pumped with a $400 \mu$ m diameter fiber-coupled diode delivering up to $30 \mathrm{~W}$ (Lissotschenko Mikrooptic). Since we need both high gain amplificationwith gains around a few hundreds-and good energy extraction, around $25 \%$ of the pump power, the design of the amplifier is critical [27-29]. To maintain the polarization, the corner cube used between the two and four passes consists of a bulk high-reflection dielectric-coated corner cube instead of a standard silver-coated retroreflector. Another critical point for micromachining application concerns the spatial profile of the amplified beam [30-34]. For all these reasons, the design chosen for this amplifier consists of a 3D multipass configuration, longitudinally pumped by a fiber-coupled diode as shown in Fig. 3 .

This simple and compact design takes advantage of the high emission cross section of the $\mathrm{Nd}: \mathrm{YVO}_{4}$. The test performed at $4 \mathrm{MHz}$ indicated an extractable energy up to $1 \mu \mathrm{J}$ for the two-pass amplifier and up to $1.8 \mu \mathrm{J}$ for the four passes.

Figure $\underline{4}$ indicates that the first two passes give the high gain and the next three and four passes are used mainly for energy extraction. For $1.25 \mathrm{~W}$ incident power, we achieved an extraction of $22 \%$ of the incident pump power corresponding to an average power of $7.3 \mathrm{~W}$ (Fig. 4). In this case the amplifier clearly operates in the extraction regime since the gains are four for two passes and six for four passes. This relatively good extraction in only four passes may be explained by the 3D geometry of the amplifier. The laser beam and the pump beam are spatially wellmatched. In fact, the cone of the diverging pump beam is uniformly filled in all the space thanks to the symmetry of the injected beams in both the $x$ and the $y$ directions.

Another advantage given by the symmetry of the 3D multipass amplifier concerns the beam profile. Actually, in general, this point is particularly critical for geometrical multipass amplifiers very sensitive to the uniformity of the pump beam (which is not the case for a regenerative amplifier where the beam is an eigenmode of the cavity). In the case of our amplifier longitudinally pumped by a fiber-coupled diode, the level of symmetry of the 3D system helps to improve the quality of the beam. In fact, as shown in Fig. $\underline{5}$, the beam after the four passes is perfectly

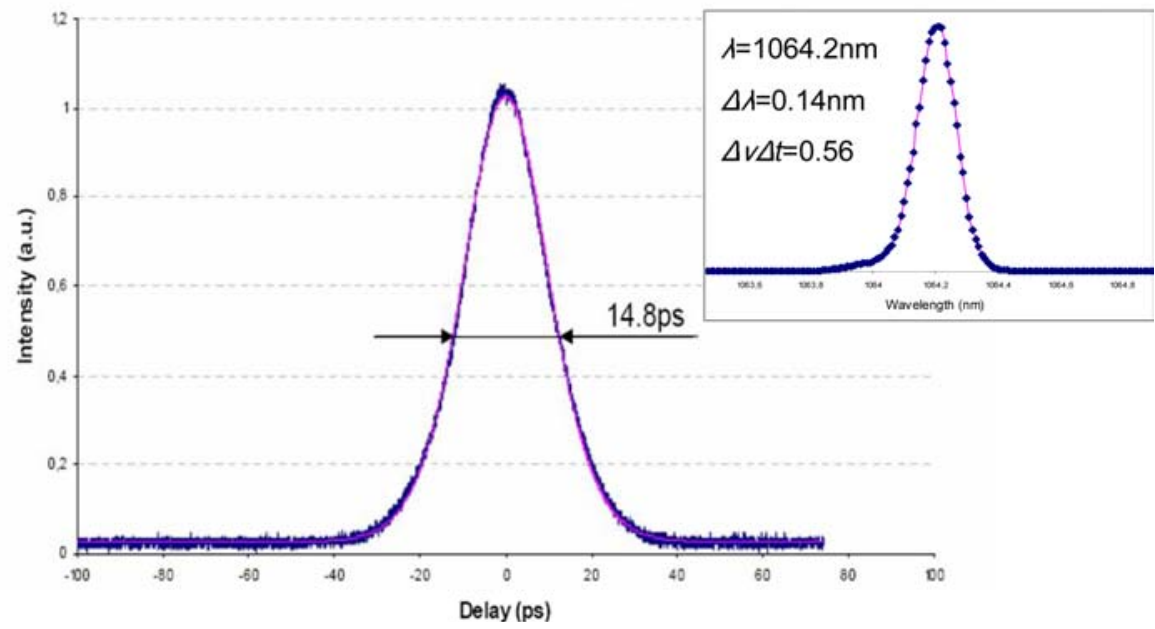

Fig. 2. (Color online) Autocorrelation trace and sech profile fit. Inset: spectrum of the $3.65 \mathrm{MHz}$ oscillator. 


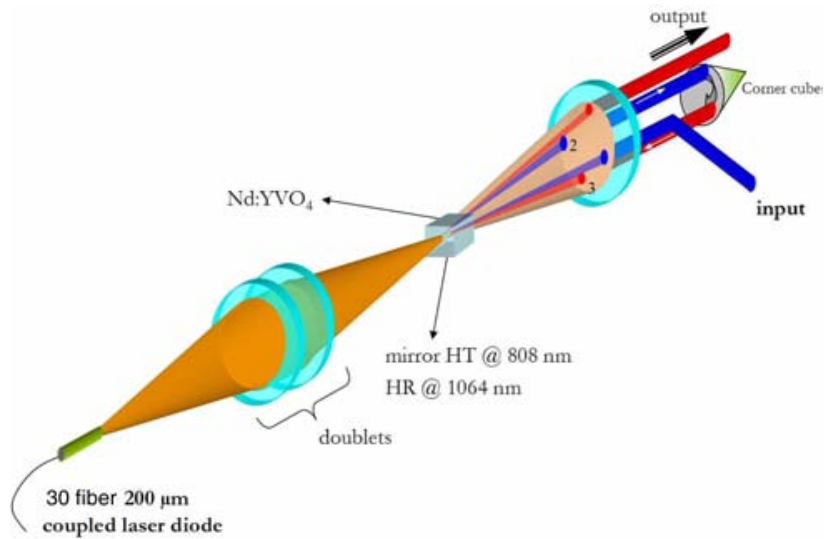

Fig. 3. (Color online) Experimental setup of the 3D multipass amplifier.

circular in the far field. The $M^{2}$ factor of this beam is 1.27 .

The maximum energy at $4 \mathrm{MHz}$ after the four passes is $1.8 \mu \mathrm{J}$, i.e., $120 \mathrm{~kW}$ peak power. The energy can be straightforwardly increased by reducing the repetition rate with the AOM, which is equivalent to increasing the stored energy in the amplifier crystal between two incident pulses. As shown in Fig. 6 , the energy saturated around $80 \mu \mathrm{J}$ for a repetition rate equal to half of the inverse of the lifetime of $\mathrm{Nd}: \mathrm{YVO}_{4}(90 \mu \mathrm{s}$ for low doped crystal). This corresponds to a maximum peak power of 5.3 MW.

At low repetition rate the gain reaches 228 for two passes and 485 for four passes. The repetition rate and the energy can then be simply tuned, with the only condition of being under the curve represented in Fig. 6, using the AOM for the repetition rate and the amplifier pump power for the energy. The potential of this versatile source has been tested for material processing applications with different materials.

\section{Material Processing Applications}

Simple and preliminary processing experiments were performed to study the influence of the repetition rate (i.e., energy per pulse) on the machining quality for $\mathrm{Al}, \mathrm{Cu}$, paper, and glass. The samples were placed on a spinning wheel and machined at

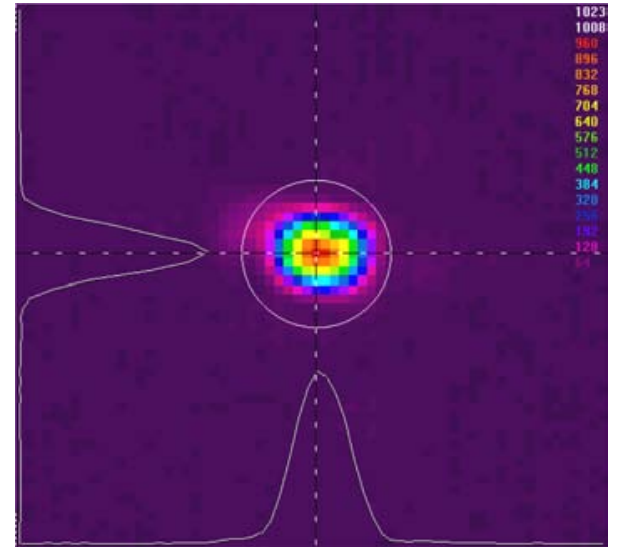

Fig. 5. (Color online) Beam profile after the four passes measured in the far field.

1,10 , and $100 \mathrm{kHz}$, and $1 \mathrm{MHz}$. Figure 7 presents a picture of this setup. Up to $100 \mathrm{kHz}$, a plasma was obtained in air when focusing with an $8 \mathrm{~mm}$ focal length objective, as shown in Fig. 7, indicating a peak power density greater than $10^{14} \overline{\mathrm{W}} / \mathrm{cm}^{2}$.

The first demonstration of micromachining has been performed in metals: $\mathrm{Al}$ and $\mathrm{Cu}$. These two metals are interesting because of their very different behaviors. With $\mathrm{Al}$, which is a "hard" metal, we expect to see the limits of the systems for low energy pulses (e.g., at high repetition rate). With $\mathrm{Cu}$, which is a "soft" metal and easily melted, we expected to see the limit of the system both in single shot ablation and for high average powers. Figure 8 represents the results obtained in $\mathrm{Al}$ for three different repetition rates. At $1 \mathrm{MHz}$, the energy per pulse $(3 \mu \mathrm{J})$ was too weak, and only a thin surface was ablated. At $100 \mathrm{kHz}$ with $9 \mu \mathrm{J}$ pulses the drilling started to be efficient and a $15 \mu \mathrm{m}$ broad groove appeared. At $10 \mathrm{kHz}$ with $60 \mu \mathrm{J}$ pulses the drilling was very efficient and a $12 \mu \mathrm{m}$ broad deep groove with relatively nice edges is observed.

Figure 9 represents the results obtained in $\mathrm{Cu}$ for three different repetition rates. At $1 \mathrm{MHz}$ a groove was observed but the amount of power ( $3 \mathrm{~W}$ incident) was important and a border lip was visible on the edges of the groove. For $\mathrm{Cu}, 10 \mathrm{kHz}$ with $60 \mu \mathrm{J}$ pulses represented a good compromise between energy and
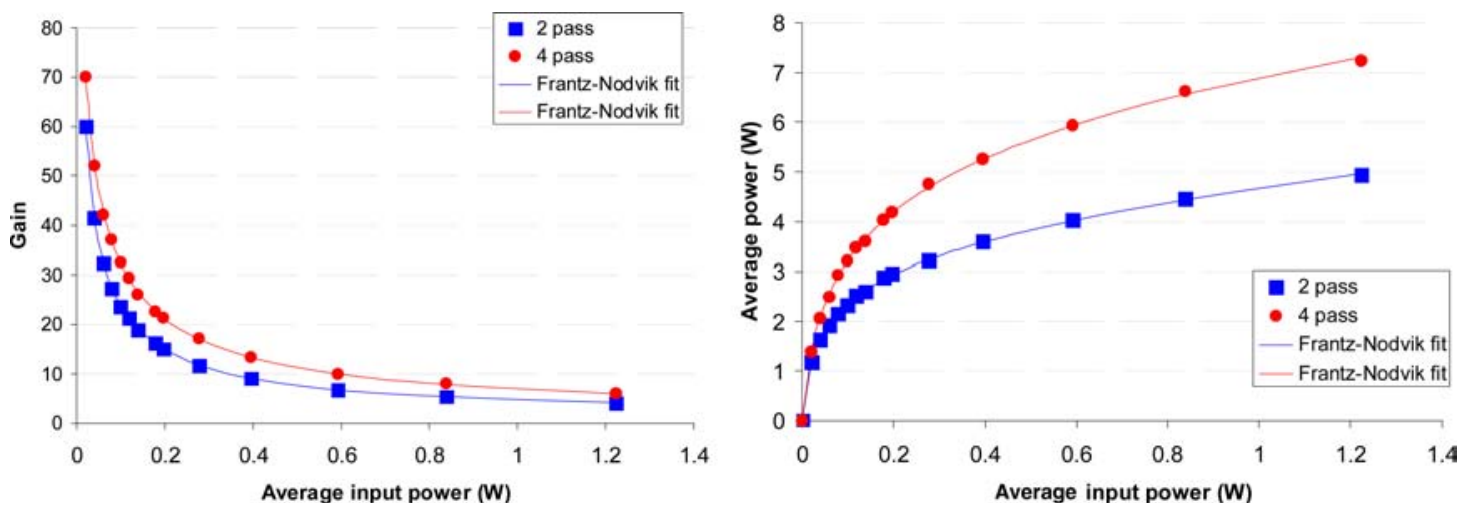

Fig. 4. (Color online) Performance of the 3D multipass amplifier operating at $4 \mathrm{MHz}$ for two or four passes. Left: gain versus incident power; right: output average power versus incident power. 


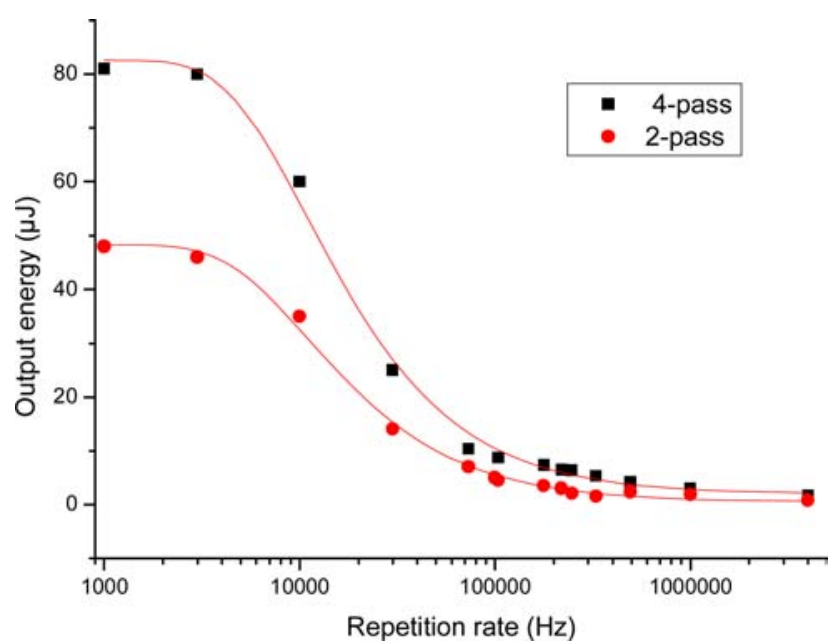

Fig. 6. (Color online) Output energy after the two- and four-pass amplifier versus the repetition rate.

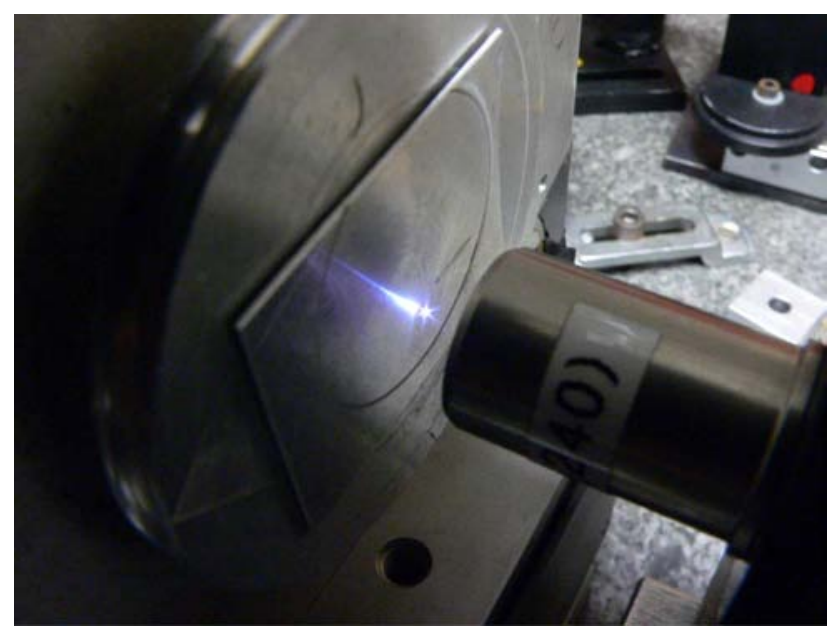

Fig. 7. (Color online) Photograph of the setup used for material processing. In this photograph the laser is focused $1 \mathrm{~mm}$ before the target to visualize the plasma in the air at the focused spot. repetition rate. In this case, the drilling was very efficient and a $12 \mu \mathrm{m}$ broad deep groove with relatively nice edges could be observed. To visualize the impact of a high energy single shot in this soft metal, $1 \mathrm{kHz}$ processing is also represented. Twenty micrometer diameter circular holes have been observed.

The second demonstration of processing was performed on papers (Fig. 10). The first experiment to be demonstrated used standard $80 \mathrm{~g} / \mathrm{m}^{2}$ paper. The precision of cutting was measured at $19 \mu \mathrm{m}$ with very sharp edges less than $2 \mu \mathrm{m}$ thick.

The third demonstration of processing has been performed in glass. For the purpose of macroscopically visible glass engraving, we studied the processing at $10 \mathrm{kHz}$ repetition rate with this source. With this energy the single impact size is around $50 \mu \mathrm{m}$ (see Fig. 11). Nevertheless, in order to observe the width of the engraving, the process was studied for different translation speeds of the sample. In fact, when lowering the translation speed of the sample, a stress transfer between neighboring impacts occurs, leading to a narrower connect line and an increased quality of the engraving as shown in Fig. 11.

\section{Conclusion}

A combination of $\mathrm{Nd}: \mathrm{YVO}_{4}$ low repetition rate oscillators, a Nd: $\mathrm{YVO}_{4} 3 \mathrm{D}$ amplifier, and an $\mathrm{AOM}$ was demonstrated to be a straightforward solution for developing a completely passive laser source easily tunable at a repetition rate producing high energy pulses that would find a wide range of applications, especially in materials processing. First, we described the performance and advantages of a very low repetition rate oscillator based on a dual modelocking technique combining both SESAM and quadratic polarization switching. This combined technique improves the mode-locked range compared
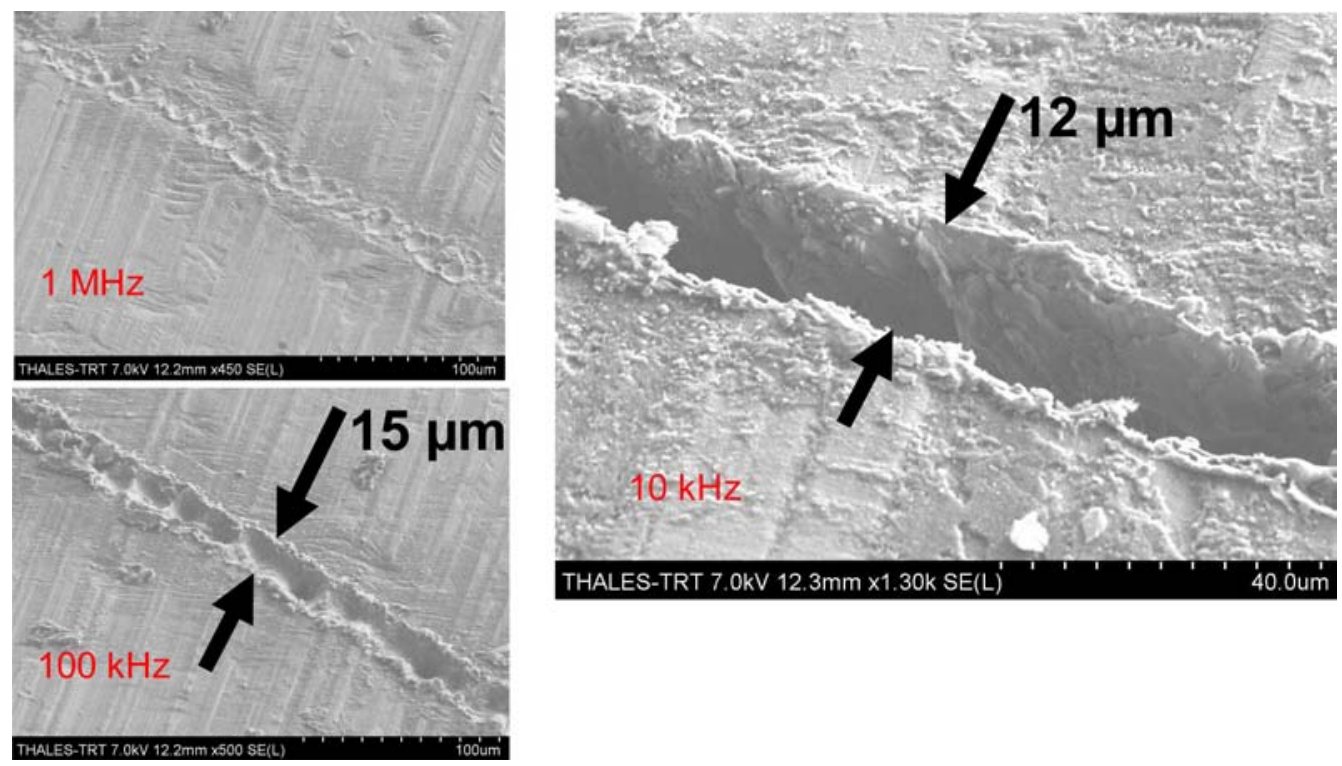

Fig. 8. (Color online) Photograph of micromachining in $\mathrm{Al}$ for three different repetition rates: $1 \mathrm{MHz}, 100 \mathrm{kHz}$, and $10 \mathrm{kHz}$. 

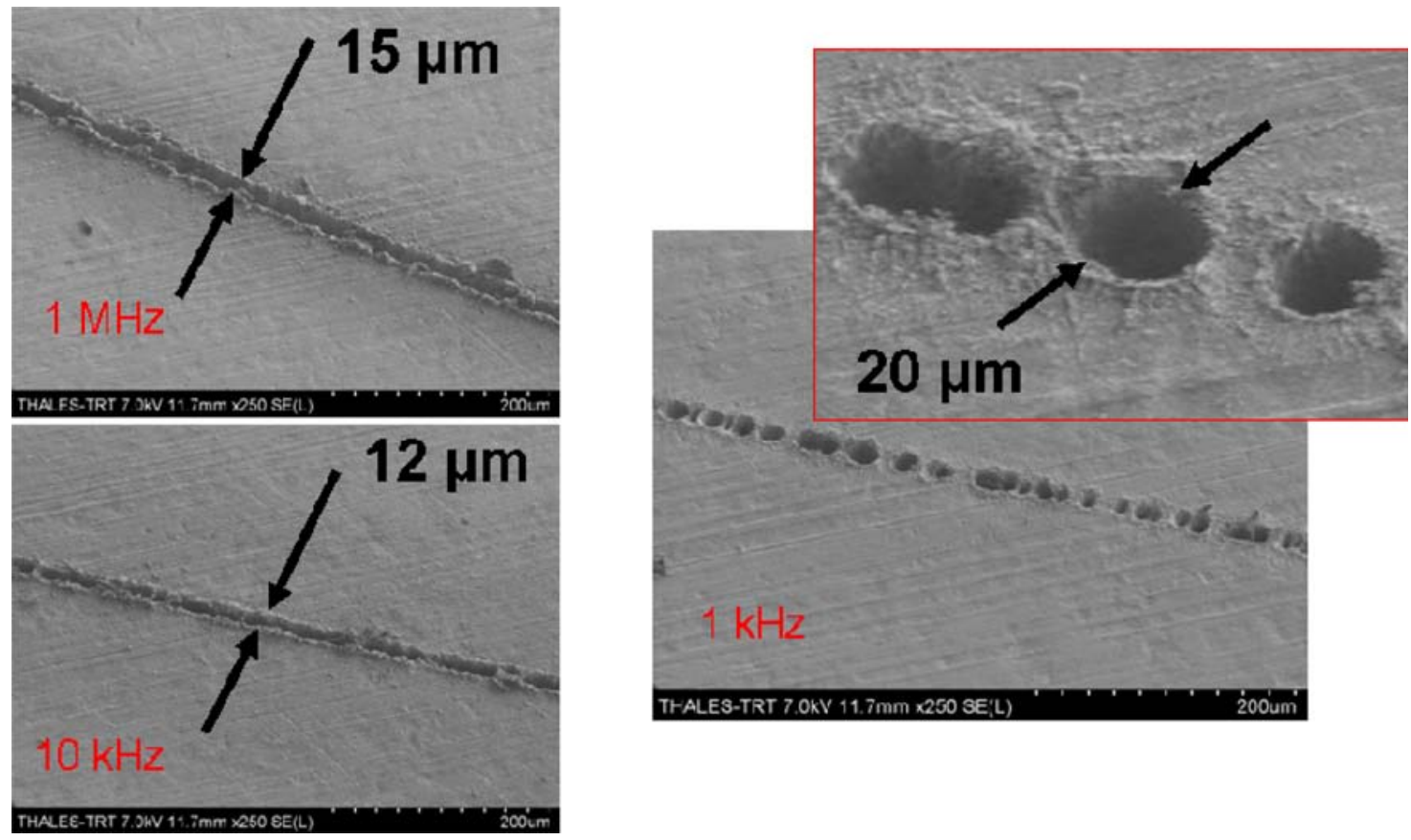

Fig. 9. (Color online) Photograph of micromachining in $\mathrm{Cu}$ for three different repetition rates: $1 \mathrm{MHz}, 10 \mathrm{kHz}$, and $1 \mathrm{kHz}$.

to single-technique mode-locked Nd: $\mathrm{YVO}_{4}$ lasers and is of interest for robust industrial applications. Moreover, relaxing the tolerance of the pulse fluence on the SESAM, this dual-mode-locking technique seems to be very suitable to reduce the risk of damage for the SESAM. By introducing the Nd: $\mathrm{YVO}_{4} 3 \mathrm{D}$ amplifiers the average output power and the energy per pulse were improved. Because of its configuration the amplifier is straightforward and easy to use after alignment. In addition, no electro-optic device is involved in the setup that could limit the repetition rate, as it occurs in a regenerative amplifier. By varying the pump power, a wide range of output peak powers and equivalently pulse energies can be

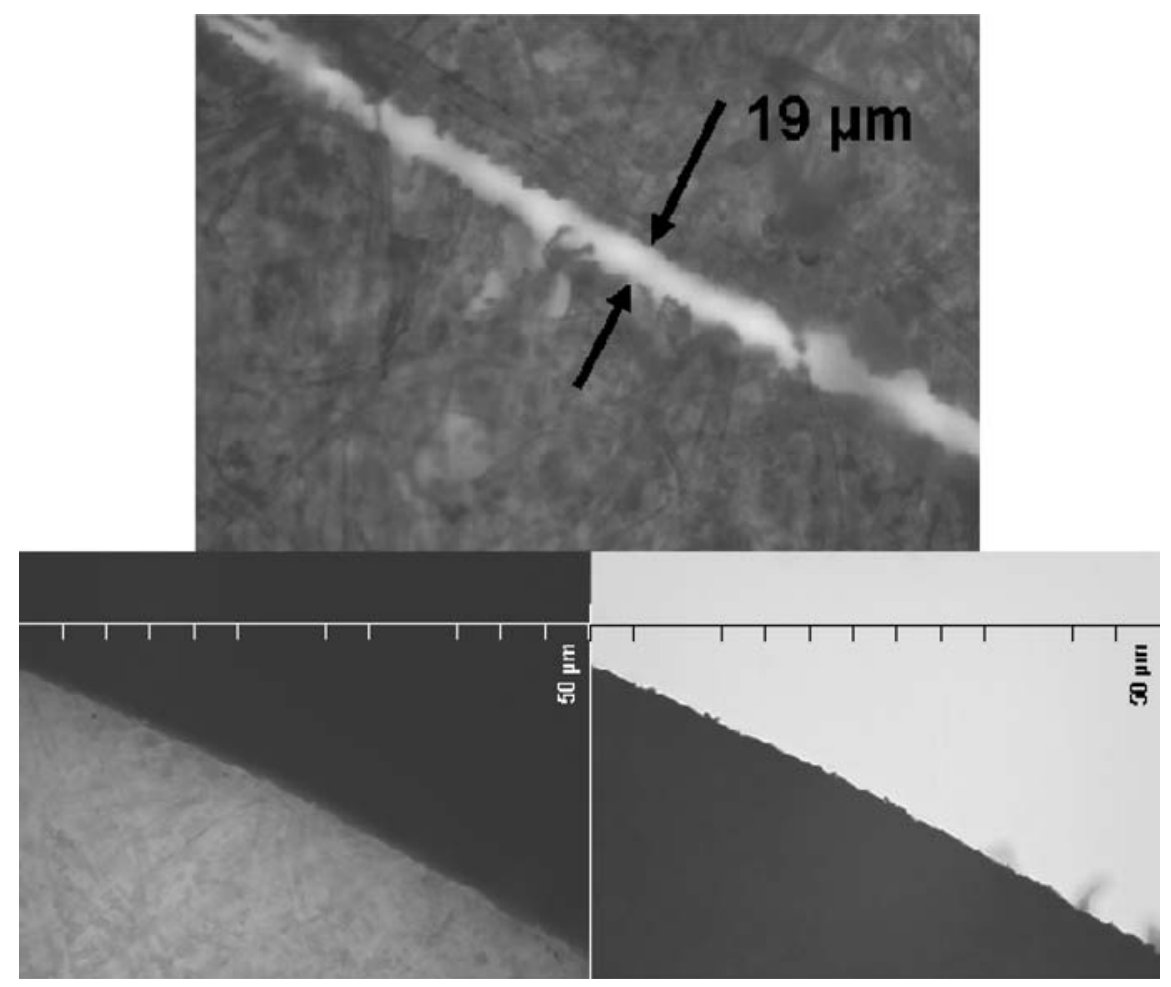

Fig. 10. Photograph of cutting in paper. Top: partial cut; bottom: edge of full cut paper frontside (left) and backside (right) illuminated. 


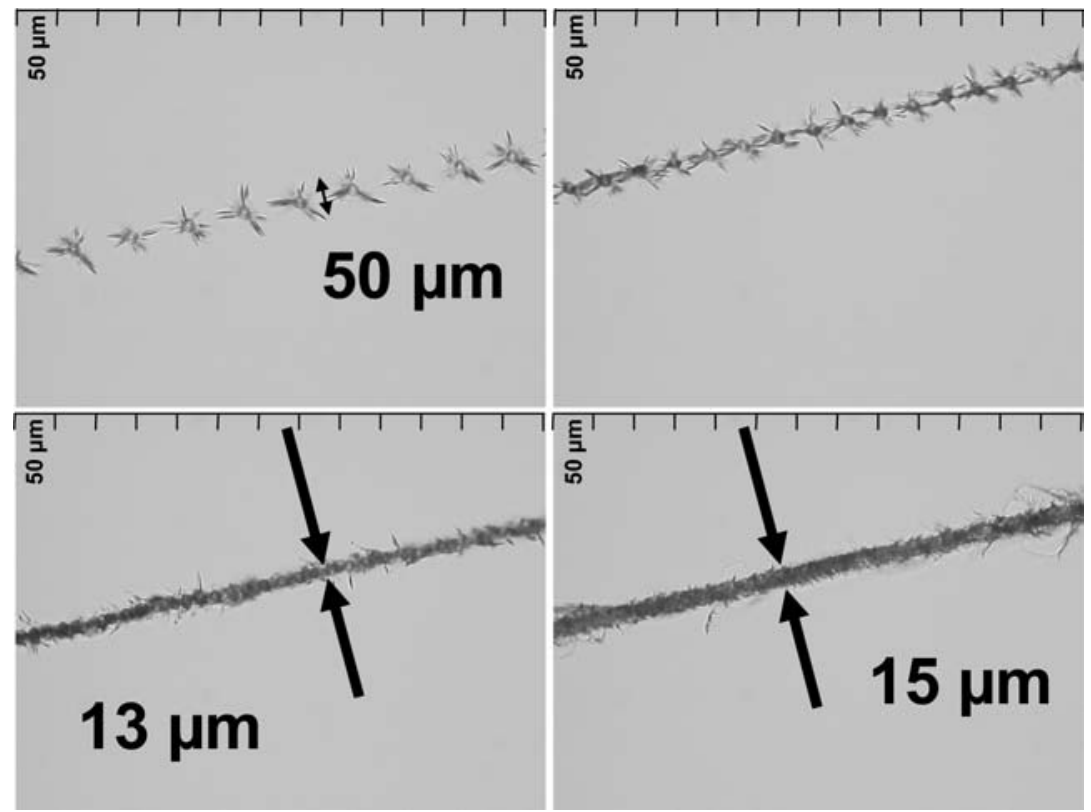

Fig. 11. Photograph of engraving glass at $10 \mathrm{kHz}$ for four different translation speeds of the sample. The speeds of the sample are from top left to bottom right: $0.45,0.3,0.12$, and $0.08 \mathrm{~m} / \mathrm{s}$.

achieved by taking advantage of the $3 \mathrm{D}$ setup that provides high gain, high energy extraction, and very good beam quality. Subsequently the source was tested to process different materials. The source was tested to micromachine $\mathrm{Al}$ and $\mathrm{Cu}$ for different repetition rates to see the optimal operation range and the limitations. Some paper cutting and glass marking have been tested to show the precision of the source for potential applications in prevention against forgery.

This work has been partially supported by the Conseil Général de l'Essonne under the Action de Soutien à la Technologie et à la Recherche en Essonne (ASTRE) program and the research program Pôle Laser from the Contrat Plan Etat Région (2000-2006).

\section{References}

1. F. Dausinger, F. Lichtner, and H. Lubatschowski, eds., Femtosecond Technology for Technical and Medical Applications, (Springer Verlag, 2004).

2. B. N. Chichkov, C. Momma, S. Nolte, F. von Alvensleben, and A. Tünnermann, "Femtosecond, picosecond and nanosecond laser ablation of solids," Appl. Phys. A 63, 109-115 (1996).

3. F. Dausinger, H. Hügel, and V. Konov, "Micromachining with ultrashort laser pulses: from basic understanding to technical applications," Proc. SPIE 5147, 106-114 (2003).

4. S. Nolte, C. Momma, H. Jacobs, A. Tünnermann, B. N. Chichkov, B. Wellegehausen, and H. Welling, "Ablation of metals by ultrashort laser pulses,” J. Opt. Soc. Am. B 14, 2716-2722 (1997).

5. J. König, S. Nolte, and A. Tünnermann, "Plasma evolution during metal ablation with ultrashort laser pulses," Opt. Express 13, 10597-10607 (2005).

6. P. B. Corkum, F. Brunel, N. K. Sherman, and T. ShrinivasanRao, "Thermal response of metals to ultrashort-pulse laser excitation," Phys. Rev. Lett. 61 (2886-2889 (1988).
7. D. Giguère, G. Olivié, F. Vidal, S. Toetsch, G. Girard, T. Ozaki, J.-C. Kieffer, O. Nada, and I. Brunette, "Laser ablation threshold dependence on pulse duration for fused silica and corneal tissues: experiments and modeling," J. Opt. Soc. Am. A 24, 1562-1568 (2007).

8. K. Furusawa, K. Takahashi, H. Kumagai, K. Midorikawa, and M. Obara, "Ablation characteristics of $\mathrm{Au}, \mathrm{Ag}$, and $\mathrm{Cu}$ metals using a femtosecond Ti:sapphire laser," J. Appl. Phys. 69 S359-S366 (1999).

9. A. Courjaud, C. Hoenninger, and E. Mottay, " $1 \mathrm{~mJ}$, multi-Khz, sub-500 fs diode-pumped ytterbium laser amplifier," presented at the 25th international congress on applications of lasers and electro-optics (ICALEO 2006), Scottsdale, Arizona, 30 October-2 November 2006; www.amplitude-systemes.com.

10. C. Momma, B. N. Chichkov, S. Nolte, F. von Alvensleben, A. Tünnermann, H. Welling, and B. Wellegehausen, "Short-pulse laser ablation of solid targets," Opt. Commun. 129, 134142 (1996)

11. Time-Bandwidth Products, www.time-bandwidth.com.

12. L. Shah, M. E. Fermann, J. W. Dawson, and C. P. J. Barty, "Micromachining with a $50 \mathrm{~W}, 50 \mu \mathrm{J}$, subpicosecond fiber laser system," Opt. Express 14, 12546-12551 (2006).

13. T. Herrmann and B. Klimt, "Micromachining with picosecond lasers: precise, cost efficient, industrially reliable," in LUMERA LASER: Laser Technik Journal (Wiley-VCH,), www.lumera-laser.com.

14. F. Dausinger, "Femtosecond technology for precision manufacturing: fundamental and technical aspects," Proc. SPIE 4830, 471-478 (2003).

15. B. Le Drogoff, F. Vidal, S. Laville, M. Chaker, T. Johnston, O. Barthélemy, J. Margot, and M. Sabsabi, "Laser-ablated volume and depth as a function of pulse duration in aluminum targets," Appl. Opt. 44, 278-281 (2005).

16. D. Breitling, C. Föhl, F. Dausinger, T. Kononenko, and V. Konov, "Drilling of metals," in Femtosecond Technology for Technical and Medical Applications, F. Dausinger, F. Lichtner, and H. Lubatschowski, eds. (Springer Verlag, 2004), pp. 131156.

17. C. Föhl, D. Breitling, K. Jasper, J. Radtke, and F. Dausinger, "Precision drilling of metals and ceramics with short and 
ultrashort pulsed solid-state lasers," Proc. SPIE 4426, 104 107 (2002).

18. S. Nolte, C. Momma, G. Kamlage, A. Ostendorf, C. Fallnich, F. von Alvensleben, and $\mathrm{H}$. Welling, "Polarization effects in ultrashort-pulse laser drilling," J. Appl. Phys. 68, 563-567 (1999).

19. S. Nolte, M. Will, J. Burghoff, and A. Tünnermann, "Ultrafast laser processing: new options for three-dimentional photonics structure," J. Mod. Phys. 10, 2533-2542 (2004).

20. C. Gerhard, F. Druon, P. Georges, V. Couderc, and P. Leproux, "Stable mode-locked operation of a low repetition rate diodepumped $\mathrm{Nd}: \mathrm{GdVO}_{4}$ laser by combining quadratic polarisation switching and a semiconductor saturable absorber mirror," Opt. Express 14, 7093-7098 (2006).

21. U. Keller, K. J. Weingarten, F. X. Kärtner, D. Kopf, B. Braun, I. D. Jung, R. Fluck, C. Hönninger, N. Matuschek, and J. Aus der $\mathrm{Au}$, "Semiconductor saturable absorber mirrors (SESAM's) for femtosecond to nanosecond pulse generation in solid-state lasers,” IEEE J. Sel. Top. Quantum Electron. 2, 435-453 (1996).

22. V. Couderc, O. Guy, E. Roisse, and A. Bartélémy, "Modelocking of CW Nd:YAG laser using nonlinear polarisation evolution in type II frequency doubling crystal," Electron. Lett. 34, 672677 (1998).

23. V. Couderc, A. Albert, and A. Barthélémy, "Low repetition rate of a mode locked Nd:YAG laser using quadratic polarization switching," Opt. Commun. 220, 413-417 (2003).

24. V. Couderc, A. Bartélémy, and F. Louradour, “2.8 ps pulses from a mode-locked diode pumped $\mathrm{Nd}: \mathrm{YVO}_{4}$ laser using quadratic polarization switching," Opt. Commun. 166, 103-111 (1999).

25. D. N. Papadopoulos, S. Forget, M. Delaigue, F. Druon, F. Balembois, and P. Georges, "Passively mode-locked diode- pumped $\mathrm{Nd}: \mathrm{YVO}_{4}$ oscillator operating at an ultralow repetition rate," Opt. Lett. 28, 1838-1840 (2003).

26. S. Forget, F. Balembois, P. Georges, and P.-J. Devilder, "A new 3D multipass amplifier based on Nd:YAG or Nd:YVO $\mathrm{YV}_{4}$ crystals," Appl. Phys. B 75, 481-485 (2002).

27. A. Agnesi, L. Carrà, F. Pirzio, D. Scarpa, A. Tomaselli, G. Reali, C. Vacchi, and C. Braggio, "High-gain diode-pumped amplifier for generation of microjoule-level picosecond pulses," Opt. Express 14, 9244-9249 (2006).

28. H. Plaessmann, S. A. Re, J. J. Alonis, D. L. Vecht, and W. M. Grossman, "Multipass diode-pumped solid-state optical amplifier," Opt. Lett. 18, 1420-1422 (1993).

29. A. Killi, J. Dörring, U. Morgner, M. Lederer, J. Frei, and D. Kopf, "High speed electro-optical cavity dumping of modelocked laser oscillators," Opt. Express 13, 1916-1922 (2005).

30. F. Druon, F. Balembois, P. Georges, and A. Brun, "High-repetition-rate $300-p s$ pulsed ultraviolet source with a passively $Q$-switched microchip laser and a multipass amplifier," Opt. Lett. 24, 499-501 (1999).

31. G. Smith and M. J. Damzen, "Spatially-selective amplified spontaneous emission source derived from an ultrahigh gain solid-state amplifier," Opt. Express 14, 3318-3323 (2006).

32. A. M. Scott, G. Cook, and A. P. G. Davies, "Efficient high-gain laser amplification from a low-gain amplifier by use of selfimaging multipass geometry," Appl. Opt. 40, 2461-2467 (2001).

33. J. E. Bernard and A. J. Alcock, "High-efficiency diode-pumped Nd:YVO4 slab laser," Opt. Lett. 18, 968-970 (1993).

34. Y. Ojima, K. Nawata, and T. Omatsu, "Over 10-watt picosecond diffraction-limited output from a Nd:YVO4 slab amplifier with a phase conjugate mirror," Opt. Express 13, 89938998 (2005). 